\title{
A Fuzzy Topsis Approach For Logistics Center Location Selection
}

\author{
Burak Erkayman, Atatürk University Erzurum, Turkey \\ Emin Gundogar, Sakarya University Sakarya, Turkey \\ Gökay Akkaya, Atatürk University Erzurum, Turkey \\ Mümtaz Ipek, Sakarya University Sakarya, Turkey
}

\begin{abstract}
It is clearly known that urban freight transportation has a significant role on sustainable development of urban areas. The persistent growth of the costs of freight transportation and as a result of congestion, environmental pollution and increasing inefficient usage of land in urban areas are forcing users and public authorities to develop alternative logistic solutions to relieve the freight traffic problem. Establishing logistics centers is one of these alternative solutions. Logistics centers are specific centers that various logistic based activities like distribution, storage, transportation, consolidation, handling, customs clearance, imports, exports, transit processes, infrastructural services, insurance, banking and similar commercial activities are performed. These centers are defined for national and international all logistic and related operations. Logistic centers must be settled near production and commercial centers, highways, railways, airports and if possible seaports. In this study we proposed a fuzzy TOPSIS approach to a logistics center location selection problem in eastern anatolia region of Turkey.
\end{abstract}

Keywords: logistics center; urban logistics; city logistics; fuzzy TOPSIS

\section{INTRODUCTION}

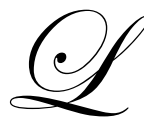

ogistics has been defined as, 'the process of strategically managing the movement and storage of materials, parts and finished inventory from suppliers, through the firm and on to customers'. Freight transport accounts, on average, for only around $40 \%$ of a company's total logistics costs. Roughly 1.75 million people worked in 'logistics and related roles' in 2003-2004. Logistics also plays a vital role in maintaining economic prosperity and social well-being [1].

Urban logistics has been defined as those movement of goods that are affected by particularities associated to urban traffic and morphology [16]. Increasing road freight vehicle number and their impacts in urban areas and cities have received more attention in recent years. Freight and passenger transportation in urban areas result several problems like social, economic, environmental and etc. Road freight vehicles operating in an urban environment generally emit a greater proportion of certain pollutants per kilometre travelled than other motor vehicles such as cars and motorcycles. This is due to their higher fuel consumption per unit of distance travelled and the fact that many of them use diesel as a fuel [2]. The growing flows of freight have been a fundamental component of contemporary changes in economic systems at the global, regional and local scales. The consideration of these changes must be made within a perspective where they are not merely quantitative, but structural and operational [3]. Some significant reasons of how important freight transportation are [2];

- $\quad$ It is fundamental to sustaining our existing life style.

- The role it plays in servicing and retaining industrial and trading activities which are essential majör wealth generating activities.

- The contribution that an efficient freight sector makes to the competitiveness of industry in the region concerned.

- The effect of freight transport and logistics costs on the cost of commodities consumed in that region. 
- The total cost of freight transport and logistics is significant and has a direct bearing on the efficiency of the economy.

- $\quad$ The environmental effect of urban freight movements (in terms of energy use and environmental impacts such as pollution, noise, visual intrusion etc.).

Rapid growth in transport is defacing cities by environmental pollution, road crashes traffic congestion, environmental emissions, due to consumption of fossil fuels. Environmental problems caused from transport could be reduced through an efficient transport system and well planned logistics centers.

Congestion and inefficient use of lands are other negative impacts of disordered urban transport. Additionally for sustainable development of the urban areas the well organization of logistics activities has a great importance.

One of the main objectives of the sustainable long term transport development program is to develop a framework for an optimal integration of different modes of transport in the regional logistics centers so as to enable efficient and cost-effective use of the transport system through seamless, customer-oriented door-to-door services, favouring competition among transport operators [4].

City logistics planning and logistics center design must be done through an interdiscipliner approach and a frame model must be built. City logistics problems can be defined as follows [5]:

Traffic congestion, environmental pollution, visual intrusion, noise pollution, air pollution, wastage of energy, separated settlement of corporations related to logistics, unweildiness of foreign trade and public formalities, additional area requirement of the ports, intermodal/multimodal terminal necessity, qualified sectoral labor force, fund necessity and economical scale, high logistics costs.

In this paper, we proposed a fuzzy decision making approach to select the best location for logistics center in northeast of Turkey according to a variety of criteria.

\section{LOGISTIC CENTERS}

\subsection{Definition Of Logistics Centers}

A logistics center is a defined area within which all activities relating to transport, logistics and the distribution of goods, both for national and international transit, are carried out by various operators. These operators can either be owners or tenants of buildings and facilities (warehouses, break-bulk centers, storage areas, offices, car parks, etc...) which have been built there [7].

Nowadays, a logistics center is perceived as an 'integrator' of various transport modes, able to promote intermodal transport. A Logistics center is mainly an intermodal terminal, which is the principal component of the intermodal transport chain, constituting the node where the transshipment of goods from one mode to the other takes place. There is a consensus in definitions that intermodal transport constitutes a transport process in which at least two of the following conditions are fulfilled [6].

- $\quad$ Two or more different transport modes (lorry, train, barge, ship, plane) are deployed.

- $\quad$ The goods remain in one and the same transport load unit for the entire journey.

Also, in order to comply with free competition rules, a logistics center must allow access to all companies involved in the activities set out above. A logistics center must also be equipped with all the public facilities to carry out the above mentioned operations. If possible, it should also include public services for the staff and equipment of the users. In order to encourage intermodal transport for the handling of goods, a logistics center must preferably be served by a multiplicity of transport modes (road, rail, deep sea, inland waterway, air). Finally, it is imperative that a logistics center be run by a single body, either public or private [7]. 
The location of the logistics centers is a key element in enhancing the efficiency of urban freight transport systems and initializing relative supply chain activities sufficiently; thus, the location of a intermodal freight logistics center should be selected carefully; otherwise it may cause irreversible consequences in the city planning and also it may create bottlenecks that lead to rapid increase in cost in providing transport solutions. All influencing factors for the determination of a location should be considered and well planned. Hence, public authorities should consider the importance of this topic by any given decision in terms of strong economical, social and environmental implications before announcing an area as a logistics center [4].

\section{FUZZY TOPSIS METHOD}

The TOPSIS [8] is widely used for tackling ranking problems in real situations. Despite its popularity and simplicity in concept, this method is often criticized for its inability to adequately handle the inherent uncertainty and imprecision associated with the mapping of the decision-maker's perception to crisp values. In the traditional formulation of the TOPSIS, personal judgments are represented with crisp values. However, in many practical cases the human preference model is uncertain and decision-makers might be reluctant or unable to assign crisp values to the comparison judgments [9]. Having to use crisp values is one of the problematic points in the crisp evaluation process. One reason is that decision-makers usually feel more confident to give interval judgments rather than expressing their judgments in the form of single numeric values. As some criteria are difficult to measure by crisp values, they are usually neglected during the evaluation. Another reason is mathematical models that are based on crisp value. These methods can not deal with decision-makers' ambiguities, uncertainties and vagueness which cannot be handled by crisp values[10]. The use of fuzzy set theory [11] allows the decision-makers to incorporate unquantifiable information, incomplete information, non-obtainable information and partially ignorant facts into decision model [12].

TFNs appear to be a valid tool, offering a well balanced compromise between computational costs and accuracy in the final ranking [13].

The steps of Fuzzy TOPSIS are as follows [14], [15]:

Step 1: Choose the appropriate linguistic variables for the alternatives with respect to criteria. The linguistic variables are described by TFNs, such as . $\tilde{x}_{i j}=\left(a_{i j}, b_{i j}, c_{i j}\right)$

Step 2: Construct the fuzzy decision matrix and the normalized fuzzy decision matrix.

$$
\tilde{R}=\left[\tilde{r}_{i j}\right]_{m \times n}
$$

Step 3: Calculate the weighted normalized fuzzy decision matrix. The weighted normalized value $\tilde{v}_{i j}$ is calculated

$$
\tilde{V}=\left[\tilde{v}_{i j}\right]_{n \times J}, i=1,2, \ldots . ., n, j=1,2, \ldots, J
$$

Step 4: Identify positive-ideal $\left(A^{*}\right)$ and negative ideal $\left(A^{-}\right)$solutions. The fuzzy positive-ideal solution (FPIS, $A^{*}$ ) and the fuzzy negative-ideal solution (FNIS, $A^{-}$) are shown in the following equations:

$$
\begin{aligned}
& A^{*}=\left\{\tilde{v}_{1}^{*}, \tilde{v}_{2}^{*}, \ldots, \tilde{v}_{i}^{*}\right\} \\
& A^{-}=\left\{\tilde{v}_{1}^{-}, \tilde{v}_{2}^{-}, \ldots, \tilde{v}_{i}^{-}\right\} \text {where } \tilde{v}_{i j}^{*}=w_{j} \otimes(1,1,1), \tilde{v}_{i j}^{-}=w_{j} \otimes(0,0,0) \text { for all } j=1,2, \ldots, n
\end{aligned}
$$


Step 5: Calculate the distance of each alternative from $A^{*}$ and $A^{-}$using following equations:

$$
\begin{aligned}
& D_{j}^{*}=\sum_{j=1}^{n} d\left(\tilde{v}_{i j}, \tilde{v}_{i}^{*}\right) \quad j=1,2, \ldots, J \\
& D_{j}^{-}=\sum_{j=1}^{n} d\left(\tilde{v}_{i j}, \tilde{v}_{i}^{-}\right) \quad j=1,2, \ldots, J
\end{aligned}
$$

Step 6: Determine the similarities to ideal solution

$$
C C_{j}=\frac{D_{j}^{-}}{D_{j}^{*}+D_{j}^{-}} \quad j=1,2, \ldots, J
$$

Step 7: Rank the preference order

\section{ILLUSTRATIVE EXAMPLE}

For illustrative example three centers (Erzurum, Diyarbakır and Malatya) are selected from the northeast region of Turkey. Evaluation criteria and sub-criteria used on logistics center location selection problem are taken from [5]. Four expert groups studied on the selection problem indicated as E1, E2, E3, E4. The hierarchical model including main criteria is illustrated in Figure 1.

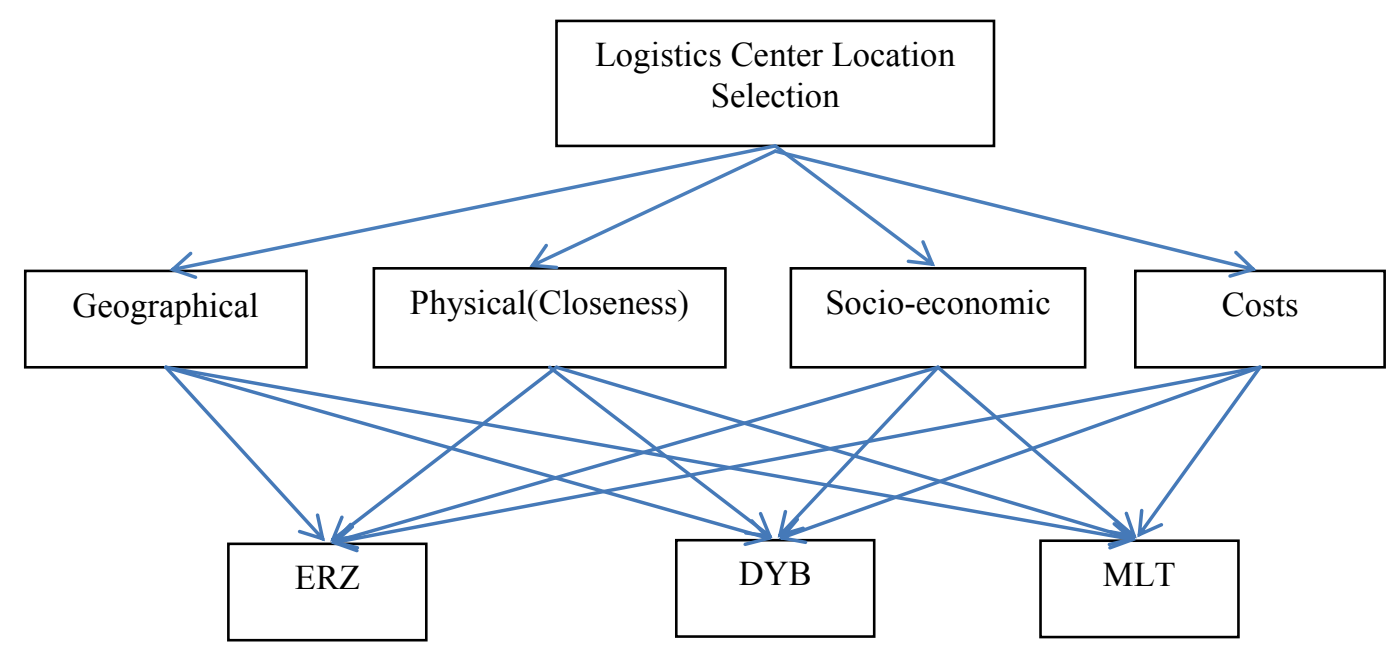

Figure 1: Hierarchical structure of the model

Table 1. Linguistic Variables For Importance Weight Of Each Criteria [14]

\begin{tabular}{|c|c|c|c|c|}
\hline VL & Lowest & 0,0 & 0,0 & 0,1 \\
\hline L & Low & 0,0 & 0,1 & 0,3 \\
\hline ML & Medium-Low & 0,1 & 0,3 & 0,5 \\
\hline M & Medium & 0,3 & 0,5 & 0,7 \\
\hline MH & Medium-High & 0,5 & 0,7 & 0,9 \\
\hline H & High & 0,7 & 0,9 & 1 \\
\hline VH & Very High & 0,9 & 1 & 1 \\
\hline
\end{tabular}


Table 2. Linguistic Variables For Importance Degrees [14]

\begin{tabular}{|c|c|c|c|c|}
\hline VP & Very Poor & 0 & 0 & 1 \\
\hline P & Poor & 0 & 1 & 3 \\
\hline MP & Medium-Poor & 1 & 3 & 5 \\
\hline F & Fair & 3 & 5 & 7 \\
\hline MG & Medium-Good & 5 & 7 & 9 \\
\hline G & Good & 7 & 9 & 10 \\
\hline VG & Very Good & 9 & 10 & 10 \\
\hline
\end{tabular}

Table 3. Fuzzy Evaluation Matrix For Geographical Properties

\begin{tabular}{|c|c|c|c|c|}
\hline & E1 & E2 & E3 & E4 \\
\hline ERZ & G & VG & G & VG \\
\hline DYB & G & MG & MG & G \\
\hline MLT & MG & F & MG & MG \\
\hline
\end{tabular}

Table 4. Fuzzy Evaluation Matrix For Physical Properties

\begin{tabular}{|c|c|c|c|c|}
\hline & E1 & E2 & E3 & E4 \\
\hline ERZ & VG & VG & G & VG \\
\hline DYB & M & MP & MP & M \\
\hline MLT & M & MP & M & M \\
\hline
\end{tabular}

Table 5. Fuzzy Evaluation Matrix For Socio-Economic Properties

\begin{tabular}{|c|c|c|c|c|}
\hline & E1 & E2 & E3 & E4 \\
\hline ERZ & G & G & VG & MG \\
\hline DYB & G & MG & F & G \\
\hline MLT & MG & G & F & MG \\
\hline
\end{tabular}

Table 6. Fuzzy Evaluation Matrix For Costs

\begin{tabular}{|c|c|c|c|c|}
\hline & E1 & E2 & E3 & E4 \\
\hline ERZ & G & G & MG & G \\
\hline DYB & G & MG & MP & M \\
\hline MLT & F & MG & G & G \\
\hline
\end{tabular}

Table 7. Determination Of Linguistic Variables Through Importance Degrees Of Criteria

\begin{tabular}{|c|c|c|c|c|}
\hline Criteria & E1 & E2 & E3 & E4 \\
\hline Geographical & H & MH & VH & VH \\
\hline Physical & VH & VH & M & M \\
\hline Socioeconomical & M & MH & ML & M \\
\hline Costs & ML & MH & \\
\hline
\end{tabular}

Table 8. Final Result Table

\begin{tabular}{|c|c|c|c|c|c|}
\hline Locations & $\boldsymbol{d}_{\boldsymbol{i}}^{*}$ & $\boldsymbol{d}_{\boldsymbol{i}}^{-}$ & Similarities to ideal solution & Point \% & Ranking \\
\hline ERZ & 1,67 & 2,62 & 0,61 & 100 & 1 \\
\hline DYB & 2,35 & 1,95 & 0,45 & 74 & 2 \\
\hline MLT & 2,43 & 1,86 & 0,43 & 71 & 3 \\
\hline
\end{tabular}

Erzurum is selected as the best logistics center with similarity to ideal solution with 0,61 . 


\section{CONCLUSIONS}

Increasing traffic level and its effects on urban areas cause social, environmental and economic problems. To overcome these problems an efficient transportation policy must be developed. For productive transportation and sustainable development, building logistics centers may provide efficient solutions to relief congestion, reduce pollution and dicrease logistic costs. Making the decision of where the logistics center must be located is fairly important and crucial for countries.

Many different traditional and novel techniques for layout or location problems proposed in the literature like AHP, TOPSIS, linear programming, integer programming, heuristic methods and etc. In this study we defined the logistics center location selection problem as MCDM problem, and proposed a fuzzy approach to solve. Decision making problems with subject to subjective evaluations must to be considered in fuzzy environment. In general the necessary data for MCDM problems are imprecise and uncertain. Solving problems through fuzzy techniques eliminates the limitation of crisp values. The importance of the model is the vagueness of the subjective decision making is taken into account by using fuzzy techniques in fuzzy environment. More dependable, more sensitive and more flexible results can be obtained through fuzzy approaches.

\section{AUTHOR BIOGRAPHIES}

Burak Erkayman has graduated Sakarya University Industrial Engineering Department. He gets his MSc from Yıldız Technical University (YTU) Systems Engineering programme. He continues $\mathrm{PhD}$ in Sakarya University Industrial Engineering programme now. His profession is on Logistics, Supply Chain and Logistics Management, Decision Support Systems and Scheduling. He is a research assistant in Ataturk University Industrial Engineering Department now.

Emin Gundogar has graduated from Istanbul Technical University (ITU) Mechanical Engineering Faculty. He gets his MSc and PhD degree from ITU Industrial Engineering programme. He has been in Stanford University CA, USA for a year for a research on Organ Allocation for Cadaveric Kidney Transplantation. He is an ERP software consultant since 1995 and works as an ERP implementation consultant for various enterprises. His profession is on ERP, Supply Chain and Logistics Management, Cost Management and Enterprise Performance Management Systems. He is a professor in Sakarya University Industrial Engineering Department now.

Gokay Akkaya has graduated from Istanbul Technical University (ITU) Industrial Engineering Department. He gets his MSc degree from Sakarya University and PhD degree from Yıldız Technical University (YTU) Industrial Engineering programme. His profession is on Operations Research, Supply Chain and Logistics Management. He is an Assist. Professor in Ataturk University Industrial Engineering Department now.

Mumtaz Ipek has graduated from Istanbul Technical University (ITU) Industrial Engineering Department. He gets his MSc degree from ITU and PhD degree from Sakarya University Industrial Engineering programme.. His profession is on Scheduling, Simulation, and programming. He is an Assist. Professor in Sakarya University Industrial Engineering Department now.

\section{REFERENCES}

1. McKinnon A., The present and future land requirements of logistical activities Land Use Policy 26S (2009) S293-S301

2. Andersson S., Allen J., Browne M. Urban logistics—-how can it meet policy makers sustainability objectives? Journal of Transport Geography 13 (2005) 71-81.

3. Hesse M., Rodrigue J.P., The transport geography of logistics and freight distribution, Journal of Transport Geography 12 (2004) 171-184.

4. Kayikci Y. A conceptual model for intermodal freight logistics center location decisions, Procedia Social and Behavioral Sciences 2 (2010) 6297-6311.

5. Bamyaci M., Tanyas M. Lojistik köy yer seçimi probleminin çözümünde çok ölçütlü karar verme yöntemleri, Loder Dergisi Say1 12, Şubat 2010. 
6. Tsamboulas D.A., Kapros S. Freight village evaluation under uncertainty with public and private financing, Transport Policy 10 (2003) 141-156. http://www.freight-village.com

7. Hwang, C. L., \& Yoon, K. (1981). Multiple attribute decision making: Methods and applications, A State of the Art Survey. New York: Springer-Verlag.

8. Chan, F. T. S., Kumar, N., Tiwari, M. K., Lau, H. C. W., \& Choy, K. L. (2007). Global supplier selection: a fuzzy-AHP approach. International Journal of Production Research. doi:10.1080/00207540600787200.

9. Dagdeviren, Yavuz,Kılınç, (2009) Weapon selection using the AHP and TOPSIS methods under fuzzy environment. Expert Systems with Applications, 36, 8143-8151.

10. Zadeh, L. A. (1965). Fuzzy sets. Information and Control, 8, 338-353.

11. Kulak, O., Durmusoglu, B., \& Kahraman, C. (2005). Fuzzy multi-attribute equipment selection based on information axiom. Journal of Materials Processing Technology, 169, 337-345.

12. Triantaphyllou, E., Lin, C.-T., 1995. Development and evaluation of five fuzzy multi-attribute decisionmaking methods. International Journal of Approximate Reasoning 14 (4), 281-310.

13. Chen, C. T. (2000). Extensions of the TOPSIS for group decision-making under fuzzy environment. Fuzzy Sets and Systems, 114, 1-9.

14. Chen, C-T., Lin, C-T., Huang, S-F., 2006. A fuzzy approach for supplier evaluation and selection in supply chain management. International Journal of Production Economics 102 (2), 289-301.

15. Munuzuri J., Larraneta J., Onieva L., Cortes P., Solutions applicable by local administrations for urban logistics improvement, Cities, Vol. 22, No. 1, p. 15-28, 2005. 